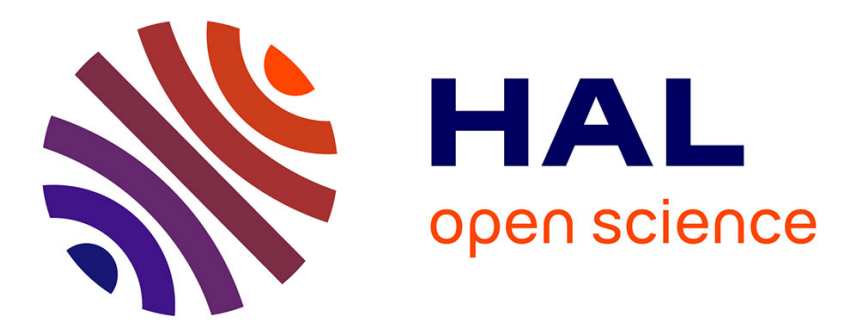

\title{
Publish or Teach?: Analysis of the Professor's Optimal Career Plan
}

Fouad El Ouardighi, Konstantin Kogan, Radu Vranceanu

\section{To cite this version:}

Fouad El Ouardighi, Konstantin Kogan, Radu Vranceanu. Publish or Teach?: Analysis of the Professor's Optimal Career Plan. 2013. hal-00823514

\section{HAL Id: hal-00823514 \\ https://essec.hal.science/hal-00823514}

Preprint submitted on 17 May 2013

HAL is a multi-disciplinary open access archive for the deposit and dissemination of scientific research documents, whether they are published or not. The documents may come from teaching and research institutions in France or abroad, or from public or private research centers.
L'archive ouverte pluridisciplinaire HAL, est destinée au dépôt et à la diffusion de documents scientifiques de niveau recherche, publiés ou non, émanant des établissements d'enseignement et de recherche français ou étrangers, des laboratoires publics ou privés. 


\section{Publish or Teach? Analysis of the Professor's Optimal Career Path}

\section{Research Center \\ ESSEC Working Paper 1307}

2013

Fouad El Ouardighi

Konstantin Kogan

Radu Vranceanu 


\title{
PUBLISH OR TEACH? ANALYSIS OF THE PROFESSOR'S OPTIMAL CAREER PATH
}

\author{
FOUAD EL OUARDIGHI* \\ ESSEC Business School, \\ Avenue Bernard Hirsch, 95021, Cergy Pontoise, France \\ KONSTANTIN KOGAN \\ Bar-Ilan University, Faculty of Social Sciences, \\ Ramat-Gan, 52900, Israel \\ RADU VRANCEANU \\ ESSEC Business School, \\ Avenue Bernard Hirsch, 95021, Cergy Pontoise, France
}

\begin{abstract}
This paper analyzes how faculty members dynamically allocate their efforts between improving their research and teaching skills, taking into account the organizational structures and incentives implemented by academic institutions. The model builds on the assumption that organizational structures have an impact on the nature of spillover effects between teaching and research competencies. We analyze the dynamic equilibrium under unilateral and bilateral spillovers, using the no-spillover case as a benchmark. The bilateral spillover case is the most appealing as it achieves the highest overall performance; however, the nature of the equilibrium and the career paths can be quite different depending on the parameters of the problem such as the obsolescence of competencies or the strength of the spillover effect. This finding provides interesting insights on what could be the most productive configuration of a higher education institution.
\end{abstract}

Keywords. Teaching, Research, Competency spillovers, Effort allocation, Faculty management.

JEL Classification. J22, C61, I23, M52

\footnotetext{
* Corresponding author Tel.: +331 34433320 Fax: +331 34433001 E-mail: elouardighi@essec.fr
} 


\section{Introduction}

Following a tradition that can be traced back to the Prussian University, contemporary higher education institutions have a twofold goal: to produce and disseminate knowledge. They generally hire a limited number of professors, each of whom has a given amount of time to devote to teaching and research activities. To determine whether an institution's overall performance is better achieved by a group of professionals that is comprised of specialized teachers and specialized researchers or by a relatively homogenous population of professionals who will undertake both teaching and research responsibilities, academic institutions must take into account the way faculty members allocate their efforts between research and teaching. In this respect, a key issue is whether, in the process of the individual performing teaching and research, mutual spillovers between research and teaching competencies can naturally occur.

From an epistemological perspective, research activity may be referred to as a mental process involving rationality and critical thinking, which aims to overcome epistemological obstacles through the scientific method (Bachelard, 1934), thus enabling the discontinuous shift between 'biodegrading' truths (Popper, 1934) or paradigms (Kuhn, 1962). On the other hand, teaching, or the diffusion of scientific knowledge, requires efforts of communication and extraversion. Teaching is the activity through which the scientific message is conveyed to non-scientists, and it implies a mental process made up of patterns and ontological convictions (Bachelard, 1934). Thus, teaching requires a lesser degree of abstraction and the introduction of shortcuts (Boudon, 1994), both of which may lead to some distortion of scientific knowledge.

These reflections suggest that the permanent cognitive compromises required for effective teaching may be incompatible with the rigorous abstraction standards necessary for sophisticated research. This assumption is supported by Friedrich and Michalak (1983) who find in an empirical study that, from the students' perspective, researchers appear to be less 
"knowledgeable" than non-researchers, and their lectures or classes are considered less efficient in conveying knowledge. Furthermore, Fairweather (2002) observes that the number of professors displaying high efficiency in both research and teaching is rather small. In his view, this basic fact of life suggests that there is no mutually reinforcing effect between the two activities. Marsh and Hattie (2002) worked out a thorough study covering 182 academics and found a statistically non-significant correlation between teachers' ratings and their total number of publications (see also Hattie and Marsh, 1996). They conclude that "the common belief that research and teaching are inextricably entwined is an enduring myth. At best, research and teaching are very loosely coupled” (Marsh and Hattie, 2002).

Other scholars have, nevertheless, upheld the opposite view according to which the two competencies would come with positive spillovers. For instance, Paul and Rubin (1984) and Demski and Zymmerman (2000) argue that research capabilities would improve teaching effectiveness, while Becker and Kenedy (2006) claim that teaching can provide substantial research insights.

If there is no definitive conclusion on the existence of natural mutual spillovers between research and teaching competencies at the individual level, we know that the management of academic institutions can manipulate the process through which faculty members accumulate professional competencies. Indeed, management can establish organizational structures that favor the transfer of competencies between teaching and research. For instance, the development of a Master of Science or a $\mathrm{PhD}$ program allows for powerful spillovers from research to teaching competency (Arnold, 2008). Conversely, spillovers from teaching to research competency can occur for instance if the school's management implements a system for supporting case writing or encourages students to support professors' research by working as research assistants, participating to experimental studies, etc. At the micro layer, if the best researchers are required to participate to teaching related meetings, or if teaching faculty is 
encouraged to attend research seminars, this could provide efficient ways of using one individual's competency to improve on his secondary competency.

While leading academic institutions generally are able to favor the emergence of bilateral spillovers, i.e., both from teaching to research competency and vice versa, many academic institutions maintain a focus on undergraduate or vocational teaching where spillovers from research to teaching and from teaching to research are extremely weak. As an approximation, if one spillover effect is weak, in a more formal model we will consider that there is no spillover. Thus, depending on the resources of the school and the quality of its top management, four plausible "stylized" situations can be considered: bilateral spillovers where teaching and research mutually reinforce each other, no spillovers where there are no mutually reinforcing transfers of competencies, and two cases of unilateral transfers, where only research (teaching) has a positive impact on teaching (research).

This paper analyzes how a faculty member's optimal effort allocation between teaching and research over the course of his or her career is affected by institutionally based spillovers. It will be shown that the existence of bilateral spillovers has a critical impact on the type of equilibrium observed and thus on the performance of the individuals and the institution.

Our work is related to Becker (1975), McDowell and Melvin (1983), Maske et al. (2003), Beath et al. (2003) and Gautier and Wauthy (2007) who analyze the professor-time allocation problem in a static framework. While their approaches provide many useful insights into the issue of faculty management, they do not take into consideration the investment in human capital, which is a major feature of academic production. The capacity to change is an important feature of faculty members, and their decisions about how much to invest in teaching and/or in research impact their careers. Professors can and do move between effort profiles over time depending on their abilities, the existing organizational structures, their 
incentives and their constraints. Figure 1 presents a highly stylized typology of academic profiles that matches the commonly used academic assessment criteria.

Broadly speaking, three general profiles can be considered: Apathetic, Specialized and Flexible (or Star) profiles. The Apathetic profile is characteristic of faculty members with modest track records in both academic activities. While the frequency of this profile is very small, it is not zero. Path-dependency or substantial contributions along dimension other than research and teaching can explain the positive survival rate of this category. Specialized profiles (excellence in research or excellence in teaching) correspond to faculty members who develop a strong competency in only one of the two academic activities. ${ }^{1}$ The Flexible or Star profile is comprised of professors who show excellence in both academic activities. ${ }^{2}$ From both the individual and the institutional perspective, it is difficult to rank the two specialized profiles (i.e., only being a great teacher or only being a great researcher), but the Star profile clearly dominates both, while the Apathetic profile is dominated by the other three profiles.

Figure 1. Typology of effort profiles

All things being equal, one major challenge for academic institutions is to improve the composition of the faculty such that the rate of Apathetic profiles is minimized. This raises the important question of whether institutionally based spillovers can allow a professor to avoid the Apathetic status over the course of his or her professional lifetime.

\footnotetext{
${ }^{1}$ A historical example of the genuine Researcher Type was Thornstein Veblen. Veblen produced famous scientific contributions both in economics and sociology (e.g., Veblen, 1899) but was rather unpopular as a teacher: he would start the academic year with full attendance in his classes, but by the end of the year, only two or three students were left (Aron, 1970).

${ }^{2}$ A historical example of such a Star is Frank Knight, one of the founding fathers of the "Chicago School” of Economics (Patinkin, 1973). Note that a researcher's competency may be denied over a lifetime, e.g., the celebrated case of Louis Bachelier (Courtault and Kabanov, 2002), who would definitely be in the Star category.
} 
This paper is organized as follows. The next section presents a dynamic model in which a representative professor seeks to optimize her effort allocation between research and teaching competencies over an infinite time horizon. Section 3 analyzes the long-run academic profile under unilateral and bilateral spillovers using the no spillover case as a benchmark, and policy implications are inferred for the management of faculty. Section 4 presents our conclusions.

\section{Model}

We analyze the inter-temporal decision of a utility-maximizing professor who can divide his professional effort between research and teaching. To keep the model simple, other activities, such as consulting, administrative services, student coaching, etc., are not introduced in the set of decision variables.

Let $x_{1}(t) \geq 0$ denote the scientific competency at time $t$ and $x_{2}(t) \geq 0$ denote the teaching competency at time $t$. We assume that both competencies can be observed and measured ${ }^{3}$; possible proxies for outstanding research are the number of papers published in top-tier scientific reviews or the number of citations. Course evaluations or teaching awards can be used to measure quality-adjusted teaching hours.

The research competency is described by the state equation:

$$
\dot{x}_{1}(t)=u_{1}(t)+\chi_{2} x_{2}(t)-\delta_{1} x_{1}(t), \quad x_{1}(0)=x_{10} \geq 0
$$

According to equation (1), the rate of change of scientific competency increases with the instantaneous improvement effort in research at time $t$, that is, $u_{1}(t) \geq 0$. The second term in the RHS of (1) represents the magnitude of institutionally based spillovers from the teaching to the research competency with $\chi_{2} \geq 0$. Following a standard assumption in the $R \& D$ literature (e.g., Cassiman and Veugelers, 2002), we assume a linear incoming spillover effect of teaching on research competency. The parameter $\chi_{2}$ reflects the existence of academic

\footnotetext{
${ }^{3}$ See Besancenot et al. (2009) for a discussion on whether quality in teaching and research can be observed.
} 
structures that favor the conversion of teaching-related developments into specific forms of research, e.g., teaching case production. Scientific knowledge quickly becomes obsolete (Lovell, 1973) and can, accordingly, be subject to decay due to forgetfulness or merely because paradigms evolve over time. Hence, the third term in the RHS of (1) denotes the depreciation rate with $\delta_{1}>0$ stands for the depreciation rate.

The dynamic of teaching competency is given by a similar state equation:

$$
\dot{x}_{2}(t)=u_{2}(t)+\chi_{1} x_{1}(t)-\delta_{2} x_{2}(t), \quad x_{2}(0)=x_{20} \geq 0
$$

According to equation (2), the rate of change in teaching competency increases with the instantaneous improvement effort in teaching at time $t$, that is, $u_{2}(t) \geq 0$. The second term in the RHS of (2) represents the magnitude of institutionally based incoming spillovers from research to teaching, with $\chi_{1} \geq 0$. The parameter $\chi_{1}$ reflects academic structures that promote the "pass-through" of a larger proportion of the original research output into teaching. The third term in the RHS of (2) is representative of the forgetting effect as applied to teaching competency given the ongoing progress in teaching methods. Accordingly, the coefficient $\delta_{2}>0$ represents the decay rate of the teaching capital.

Remark. In the case of no mutual spillovers between research and teaching, equations (1) and (2) reduce to standard capital accumulation models.

Finally, we introduce the following inequality constraint:

$$
u_{1}(t)+u_{2}(t) \leq 1
$$

which states that the total effort available for research and teaching activities is limited to the normalized unit value. Note that a binding effort constraint reflects a hard-working situation. We now turn to the definition of the professor's objective function. It is widely agreed that professors' rewards are positively related to both their teaching and their research performances (Becker, 1975; Gomez-Meija and Balkin, 1992; Euwals and Ward, 2005). In 
turn, teaching and research performances are related to a professor's stock of educational and scientific competencies, i.e., the two facets of their specific human capital. To keep the model as general as possible, we assume that the professor's total compensation at time $t$ depends on his status and official position in the school, and this status is related to his accumulated career achievements (or competency) in teaching and research. ${ }^{4}$ This compensation structure is representative of the currently dominant professor promotion system, where performance in research and teaching are the essential criteria for promotion and wage increases, with varying weights from one institution to another. An alternative model that focuses on performancebased schemes where schools pay “success” bonuses would link compensation to variations in output (new publications, new courses, etc). However, if schools (especially in Europe) resort more and more to such "incentive systems", this variable wage is still low compared to the fixed part of the compensation, which is connected to the human capital of the professor. Therefore, we consider that the overall compensation is comprised of:

- An instantaneous reward related to the recognition of the professor's research competency expressed as a linear function in the stock of scientific competencies, i.e., $a_{1} x_{1}(t), a_{1}>0$.

- An instantaneous reward connected to the professor's teaching competency expressed as a linear function in the stock of teaching competencies, i.e., $a_{2} x_{2}(t), a_{2}>0$.

The reward margins $a_{i}, i=(1,2)$, reflect the magnitude of the stated priorities of the school with respect to research and teaching activities. ${ }^{5}$ Furthermore, the assumption of an additive separable linear function for the professor's total remuneration is consistent with the possibility of an alternating development of academic competencies. In other words, in any

\footnotetext{
${ }^{4}$ Note that scientists also "receive psychic returns from the belief that their research is true and important" (Diamond, 1993). Merton (1957) emphasizes the importance of social recognition for scholars.

${ }^{5}$ The "research-elite" institutions, to use the typology by Beath et al. (2012), set a higher relative weight on research.
} 
time period, a given faculty member may be remunerated for both academic activities while improving only one of those competencies, that is, either research or teaching (i.e., $u_{i}(t)=0$ and $\left.0<u_{j}(t) \leq 1, i, j=(1,2), i \neq j\right)$.

We assume that scientific effort (e.g., related to the preparation of articles, books, papers for presentation) generates an instantaneous quadratic cost of $c_{1}\left[u_{1}(t)\right]^{2} / 2$, where the parameter $c_{1}>0$ inversely reflects the professor's talent for scientific research (i.e., a lower $c_{1}$ results in a lower cost for any improvement effort in research, and vice versa).

Teaching effort (e.g., related to the preparation of classes, cases studies, student supervision and coaching) also involves an instantaneous quadratic cost equal to $c_{2}\left[u_{2}(t)\right]^{2} / 2$, where the parameter $c_{2}>0$ inversely indicates the professor's talent for teaching (i.e., a lower $c_{2}$ results in a lower cost for any improvement effort in teaching and vice versa).

In this paper, we consider the case where a professor can keep his position for life. This possibility is common in the North American academic system, which has no compulsory retirement age. This is in contrast to the European context where professors must generally retire at a particular age that is fixed by law. As the end of a person's lifetime cannot be accurately predicted, the infinite time horizon $(T \mapsto \infty)$ provides a reasonable approximation of a life-long career.

The professor's optimal control problem can thus be written as follows:

$$
\operatorname{Max} U=\int_{0}^{\infty} e^{-r t} \sum_{i=1}^{2}\left\{a_{i} x_{i}(t)-c_{i}\left[u_{i}(t)\right]^{2} / 2\right\} \mathrm{d} t, \quad i=1,2
$$

subject to (1)-(2)-(3) and $u_{i}(t) \geq 0, \forall t$, where $r>0$ denotes the professor's discounting rate as the expression of his time preference. Note that the discounting rate may be connected - at least subjectively - to the tightness of institutional control mechanisms, notably the periodicity of internal assessments of performance in research and teaching, e.g., the time 
horizon assigned to various academic projects (building a new course, writing a new textbook) or the frequency of academic evaluations. In top-tier institutions, the frequency and structure of these assessments generally depend on internal rules that rarely change. The conclusions of these assessments serve as a basis for promotions, wage increases and other rewards. An important timeline, however, concerns the decision to grant tenure (see Faria et al., 2013). The longer the time span between two personal assessments, the smaller the discounting rate.

\section{Analysis}

Skipping the time index for convenience, the current-value Hamiltonian is

$$
\mathcal{H}=\sum_{i=1}^{2}\left[a_{i} x_{i}-c_{i} u_{i}^{2} / 2+\lambda_{i}\left(u_{i}+\chi_{j} x_{j}-\delta_{i} x_{i}\right)\right], \quad i, j=(1,2), i \neq j
$$

where $\lambda_{i} \equiv \lambda_{i}(t), i=1,2$ are discounted costate variables that are given by

$$
\dot{\lambda}_{i}=\left(r+\delta_{i}\right) \lambda_{i}-\chi_{i} \lambda_{j}-a_{i}, \quad i, j=(1,2), i \neq j
$$

Under our assumptions, the Lagrangian can be written:

$$
L=\not t+\eta\left(1-\sum_{i} u_{i}\right)+\sum_{i} \omega_{i} u_{i}
$$

where $\eta$ and $\omega_{i}$ are Lagrange multipliers such that $\eta\left(1-\sum_{i} u_{i}\right)=0, \eta \geq 0$, and $\omega_{i} u_{i}=0$ and $\omega_{i} \geq 0, i=1,2$.

Necessary conditions for optimality are

$$
L_{u_{i}}=-c_{i} u_{i}+\lambda_{i}-\eta+\omega_{i}=0, \quad i=1,2
$$

Note that the effort and non-negativity constraints cannot be simultaneously binding with $\eta>0$ and $\omega_{i}>0, i=1,2$ because $\sum_{i} u_{i}=1$ and $u_{i}=0, i=1,2$ cannot hold simultaneously.

On the other hand, if the effort constraint is not binding and one non-negativity constraint is binding, that is, $\eta=0, \omega_{i}>0$ and $\omega_{j}=0, i, j=(1,2), i \neq j$, this would imply $u_{i}=0$ and 
$0<u_{j}<1, i, j=(1,2), i \neq j$. Thus, the conditions in (8) can hold only if $\lambda_{i}<0$ and $\lambda_{j}>0$, $i, j=(1,2), i \neq j$. As shown below, this is not the optimal case. Finally, if $\eta=0$ and $\omega_{i}>0$, $i=1,2$, it implies that $u_{i}=0, i=1,2$, which can hold only if $\lambda_{i}<0, i=1,2$.

As a result, five cases are to be considered: the corner solution with $u_{i}=0, i=1,2$; the interior solution with $u_{i}>0$ and $\sum_{i} u_{i}<1, i=1,2$; the hard-working solution with $u_{i}>0$ and $\sum_{i} u_{i}=1, \quad i=1,2$; the full-time activity solution with $u_{i}=1$ and $u_{j}=0$, $i, j=(1,2), i \neq j$.

In the interior solution case, the necessary conditions are:

$$
u_{i}^{n b}=\lambda_{i} / c_{i}, \quad i=1,2
$$

where the superscript $n b$ refers to the interior solution. According to (9), an optimal improvement academic effort equals the ratio between the implicit benefit to improve the corresponding competency and the cost coefficient of the associated improvement effort. If $\lambda_{i}(t) \geq 0, i=1,2$, the control variables have a non-negative value. Note that the existence of an interior solution requires costate variables such that $0<\lambda_{i}<c_{i}$ and $\sum_{i} \lambda_{i} / c_{i}<1, i=1,2$. In the hard-working case, necessary conditions for optimality are:

$$
u_{i}^{b}=\left(c_{j}+\lambda_{i}-\lambda_{j}\right) / \sum_{i} c_{i}, \quad i, j=(1,2), i \neq j
$$

where the superscript $b$ refers to the hard-working case. Note that the existence of a binding solution requires that $\sum_{i} \lambda_{i} / c_{i} \geq 1$ and $-c_{j} \leq \lambda_{i}-\lambda_{j} \leq c_{i}, i, j=(1,2), i \neq j$. If $\lambda_{i}(t) \geq 0$, $i=1$, 2 , a full-time research (teaching) effort is obtained for $\lambda_{2}-\lambda_{1} \leq-c_{1}\left(\lambda_{2}-\lambda_{1} \geq c_{2}\right)$. We now compare the cases with no and with unilateral spillover and the case of bilateral spillovers. To do so, we assume a steady state, i.e., $\dot{x}_{i}=0, i=1,2$, to study an optimal control at this state. Assuming that $\dot{x}_{1}=\dot{x}_{2}=0$, we get $u_{1}=\delta_{1} x_{1}-\chi_{2} x_{2}$ and $u_{2}=\delta_{2} x_{2}-\chi_{1} x_{1}$. 
Differentiating these equations and, again, taking into account that $\dot{x}_{\dot{i}}=0$, we find that the steady state $\dot{x}_{i}=0$ implies steady effort, $\dot{u}_{i}=0, i=1,2$. Furthermore, differentiating the optimality conditions (8) over an interval of time and accounting for $\dot{u}_{i}=0$, we find that the costate variables are time invariant as well. We thus conclude with the following result.

Lemma 1. If the professor's competencies are both steady, then the corresponding costate variables are also steady, and the professor performs time invariant control efforts.

We hereafter define as the "steady state academic profile" the pair of research and teaching efforts $\left(u_{1}^{s}, u_{2}^{s}\right)$ for which there is no incentive to vary the effort in either of the two activities over the long run. Based on Lemma 1, the next lemma studies the case of unilateral spillover.

Lemma 2. Consider the case with unilateral spillover.

Let $\sum_{i} \frac{\left(r+\delta_{j}\right) a_{i}+\chi_{i} a_{j}}{c_{i} \prod_{i}\left(r+\delta_{i}\right)}<1$. The interior steady state along with the corresponding effort is

$$
\begin{array}{ll}
u_{i}^{n b s}=\frac{\left(r+\delta_{j}\right) a_{i}+\chi_{i} a_{j}}{c_{i} \prod_{i}\left(r+\delta_{i}\right)}, & u_{j}^{n b s}=\frac{a_{j}}{\left(r+\delta_{j}\right) c_{i}}, \\
x_{i}^{n b s}=\frac{\left(r+\delta_{j}\right) a_{i}+\chi_{i} a_{j}}{\delta_{i} c_{i} \prod_{i}\left(r+\delta_{i}\right)}, & x_{j}^{n b s}=\frac{\delta_{i} c_{i}\left(r+\delta_{i}\right) a_{j}+\chi_{i} c_{j}\left[\left(r+\delta_{j}\right) a_{i}+\chi_{i} a_{j}\right]}{\prod_{i} \delta_{i}\left(r+\delta_{i}\right) c_{i}},
\end{array}
$$

$i, j=(1,2), i \neq j$

Otherwise, if $\sum_{i} \frac{\left(r+\delta_{j}\right) a_{i}+\chi_{i} a_{j}}{c_{i} \prod_{i}\left(r+\delta_{i}\right)} \geq 1$, the professor is hard working and we have the two following types of steady state:

i) If $c_{j} \prod_{i}\left(r+\delta_{i}\right)+\left(r+\delta_{j}\right) a_{i}-\left(r+\delta_{i}-\chi_{i}\right) a_{j}>0$ and $c_{i} \prod_{i}\left(r+\delta_{i}\right)+\left(r+\delta_{i}-\chi_{i}\right) a_{j}-\left(r+\delta_{j}\right) a_{i}>0$, then: 
$u_{i}^{b s}=\frac{1}{\sum_{i} c_{i}}\left[c_{j}+\frac{\left(r+\delta_{j}\right) a_{i}-\left(r+\delta_{i}-\chi_{i}\right) a_{j}}{\prod_{i}\left(r+\delta_{i}\right)}\right], u_{j}^{b s}=\frac{1}{\sum_{i} c_{i}}\left[c_{i}+\frac{\left(r+\delta_{i}-\chi_{i}\right) a_{j}-\left(r+\delta_{j}\right) a_{i}}{\prod_{i}\left(r+\delta_{i}\right)}\right]$,

$x_{i}^{b s}=\frac{1}{\delta_{i} \sum_{i} c_{i}}\left[c_{j}+\frac{\left(r+\delta_{j}\right) a_{i}-\left(r+\delta_{i}-\chi_{i}\right) a_{j}}{\prod_{i}\left(r+\delta_{i}\right)}\right], x_{j}^{b s}=\frac{1}{\delta_{j} \sum_{i} c_{i}}\left[c_{i}+\frac{\left(r+\delta_{i}-\chi_{i}\right) a_{j}-\left(r+\delta_{j}\right) a_{i}}{\prod_{i}\left(r+\delta_{i}\right)}\right]$,

$i, j=(1,2), i \neq j$.

ii) If $c_{j} \prod_{i}\left(r+\delta_{i}\right)+\left(r+\delta_{j}\right) a_{i}-\left(r+\delta_{i}-\chi_{i}\right) a_{j}>0$ and $c_{i} \prod_{i}\left(r+\delta_{i}\right)+\left(r+\delta_{i}-\chi_{i}\right) a_{j}-\left(r+\delta_{j}\right) a_{i} \leq 0$,

then at the steady state, a full-time effort is devoted to competency $i$, that is, $u_{i}=1$ and $u_{j}=0$, and:

$x_{i}^{b s}=1 / \delta_{i}$,

$$
x_{j}^{b s}=\chi_{i} / \delta_{1} \delta_{2}, \quad i, j=(1,2), i \neq j
$$

\section{Proof. A1.}

Note that the analysis is symmetric, so there is no need to develop separately the cases of unilateral spillover from teaching to research and from research to teaching.

Corollary 1. Consider the case with no spillover between academic competencies.

If $\sum_{i} \frac{a_{i}}{\left(r+\delta_{i}\right) c_{i}}<1$, then

$$
u_{i}^{n b s}=\frac{a_{i}}{\left(r+\delta_{i}\right) c_{i}}, \quad x_{i}^{n b s}=\frac{a_{i}}{\delta_{i}\left(r+\delta_{i}\right) c_{i}}, \quad i=1,2
$$

Otherwise, there are two types of steady state:

i) If $c_{j} \prod_{i}\left(r+\delta_{i}\right)+\left(r+\delta_{j}\right) a_{i}-\left(r+\delta_{i}\right) a_{j}>0$, then

$$
\begin{aligned}
& u_{i}^{b s}=\frac{1}{\sum_{i} c_{i}}\left[c_{j}+\frac{\left(r+\delta_{j}\right) a_{i}-\left(r+\delta_{i}\right) a_{j}}{\prod_{i}\left(r+\delta_{i}\right)}\right], x_{i}^{b s}=\frac{1}{\delta_{i} \sum_{i} c_{i}}\left[c_{j}+\frac{\left(r+\delta_{j}\right) a_{i}-\left(r+\delta_{i}\right) a_{j}}{\prod_{i}\left(r+\delta_{i}\right)}\right],(17 \\
& i, j=(1,2), i \neq j .
\end{aligned}
$$


ii) If $\quad c_{j} \prod_{i}\left(r+\delta_{i}\right)+\left(r+\delta_{j}\right) a_{i}-\left(r+\delta_{i}\right) a_{j}>0 \quad$ and $\quad c_{i} \prod_{i}\left(r+\delta_{i}\right)+\left(r+\delta_{i}\right) a_{j}-\left(r+\delta_{j}\right) a_{i} \leq 0$,

then the full-time effort is devoted to competency $i$, that is, $u_{i}^{b s}=1$ and $u_{j}^{b s}=0$, and

$$
x_{i}^{b s}=1 / \delta_{i}, \quad x_{j}^{b s}=0, \quad i, j=(1,2), i \neq j
$$

\section{Proof. A2.}

With respect to faculty management, many institutions assume that the steady state level of a given academic competency can be improved simply by raising the reward margin related to that competency. Additionally, some institutions assume that higher research competencies can be achieved merely by raising the weight of research in promotion decisions. Most often, this elementary managerial decision-making process considers that the consequences of reward manipulation for one activity have negligible effects on the other activity. Our analysis shows that the consequences of manipulating the incentive system may be more sophisticated than assumed by the elementary reasoning.

In the case of no spillover between academic competencies, an increase in the reward margin of one academic competency increases the corresponding effort in the interior solution, as claimed by conventional wisdom. In contrast, under unilateral spillover, an increase in the reward margin of the academic competency that absorbs the spillover effect increases both efforts in the interior solution, while an increase in the reward margin of the academic competency that produces the spillover effect increases only the corresponding effort in the interior solution.

For hard-working faculty members, the differentiation of the effort constraint with respect to time implies $\dot{u}_{i}=-\dot{u}_{j}, i, j=(1,2), i \neq j$, that is, any positive variation of effort in one activity is matched by an identical reduction in effort in the other activity. Accordingly, a marginal increase in the reward margin of one academic competency increases the 
corresponding interior steady state effort, but decreases, by the same proportion, the other competency's interior steady state effort under no and unilateral spillover.

On the other hand, under no and unilateral spillover between academic competencies, a larger discounting rate reduces the interior steady state academic profile. For symmetric reward margins and depreciation rates of both competencies, the discounting rate has no influence on the hard-working steady state. In any case, it has no influence on the steady state with fulltime effort devoted to competency $i$.

Under unilateral spillover, the interior steady state increases in both academic competencies with competency i's spillover effect. As there is no substitution effect between the steady state interior efforts, an increase in the outgoing spillover effect raises the related steady state effort without reducing the steady state interior effort of the incoming spillover's competency. In the hard-working case, however, the outgoing spillover's competency is enhanced compared to the case with no spillover, while the incoming spillover's competency is lowered. This reflects a substitution effect between the steady state hard-working efforts which is similar to that resulting from a marginal increase in the reward margin of one academic competence. Finally, in the full-time activity cases, the incoming spillover's competency increases while the outgoing spillover's competency remains unchanged.

From Lemma 2 and Corollary 1, we observe that the steady state is always non-negative under unilateral or no spillover circumstances. On the other hand, under bilateral spillovers, the steady state may become negative as discussed in the following lemma. To study the optimal behavior in such a case, we add a state constraint, $x_{i} \geq 0, i=1,2$. Accordingly, the costate equations become

$$
d \lambda_{i}=\left[\left(r+\delta_{i}\right) \lambda_{i}-\chi_{j} \lambda_{j}-a_{i}\right] d t-d \mu_{i}(t), \quad i, j=(1,2), i \neq j
$$

where the measure functions $d \mu_{i}(t) \geq 0$ satisfy the complementary slackness: 


$$
\int_{0}^{\infty} x_{i}(t) \mathrm{d} \mu_{i}(t)=0, \quad i=1,2 .
$$

Let $x_{1}(t)=0$ and $x_{2}(t) \neq 0$ during a time interval. Then, from equation (1), we have $u_{1}=-\chi_{2} x_{2}$. That is, for $\chi_{2}>0$, the steady state of $x_{1}=0$ is not feasible under bilateral spillover unless $x_{2}=0$ as well.

Assume now that $x_{i}^{n b s}=0, i=1,2$, then from (1) and (2), we readily observe that, $u_{i}^{n b s}=0$, $i=1$, 2 , which meets the necessary optimality conditions (8) if $\lambda_{i} \leq 0$ and $d \mu_{i}(t) \geq 0$. To verify when these two requirements hold, we consider a solution to (19). Specifically, by setting (19) at zero, $d \lambda_{i}=\left[\left(r+\delta_{i}\right) \lambda_{i}-\chi_{j} \lambda_{j}-a_{i}\right] d t-d \mu_{i}(t)=0, i, j=(1,2), i \neq j$, we get:

$$
\dot{\mu}_{i}(t)=\left(r+\delta_{i}\right) \lambda_{i}-\chi_{j} \lambda_{j}-a_{i} . \quad i=1,2
$$

Next solving the system of two inequalities $d \mu_{i}(t) \geq 0$ for (21) we find that $d \mu_{i}(t) \geq 0$ and variables $\lambda_{i}, i=1,2$, are not positive if $\left.r \in\right] 0, \sqrt{\left(\delta_{i}-\delta_{j}\right)^{2} / 4+\chi_{1} \chi_{2}}-\Sigma_{i} \delta_{i} / 2[$. That is, if this condition holds the zero steady state is optimal. Moreover, (21) and (19) imply functions $\mu_{i}(t)$ and the costate variables are continuously differentiable. Therefore the costate property defined in Lemma 1 applies under the state constraint of $x_{i} \geq 0$.

Lemma 3. Consider bilateral spillovers between academic competencies. Let $\delta_{1} \delta_{2} \leq \chi_{1} \chi_{2}$.

i) If either $\delta_{1} \delta_{2}=\chi_{1} \chi_{2}$ or $\delta_{1} \delta_{2}<\chi_{1} \chi_{2}$ and $r \geq \sqrt{\left(\delta_{i}-\delta_{j}\right)^{2} / 4+\chi_{1} \chi_{2}}-\sum_{i} \delta_{i} / 2$, then there is no steady state.

ii) If $\delta_{1} \delta_{2}<\chi_{1} \chi_{2}$ and $\left.r \in\right] 0, \sqrt{\left(\delta_{i}-\delta_{j}\right)^{2} / 4+\chi_{1} \chi_{2}}-\sum_{i} \delta_{i} / 2[$, then the professor makes no effort at all, i.e., $u_{i}^{S}=0, i=1,2$, and the steady state is zero in both competencies.

\section{Proof. A3.}


Lemma 4. Consider the bilateral spillovers between academic competencies. Let $\delta_{1} \delta_{2}>\chi_{1} \chi_{2}$, and $\sum_{i} \frac{\left(r+\delta_{j}\right) a_{i}+\chi_{i} a_{j}}{\left[\prod_{i}\left(r+\delta_{i}\right)-\chi_{1} \chi_{2}\right] c_{i}}<1$. The interior steady state along with the corresponding efforts are then:

$$
\begin{array}{ll}
u_{i}^{n b s}=\frac{\left(r+\delta_{j}\right) a_{i}+\chi_{i} a_{j}}{\left[\prod_{i}\left(r+\delta_{i}\right)-\chi_{1} \chi_{2}\right] c_{i}}, & i, j=(1,2), i \neq j \\
x_{i}^{n b s}=\frac{\chi_{j}\left[\left(r+\delta_{i}\right) a_{j}+\chi_{j} a_{i}\right] c_{i}+\delta_{j}\left[\left(r+\delta_{j}\right) a_{i}+\chi_{i} a_{j}\right] c_{j}}{\left(\delta_{1} \delta_{2}-\chi_{1} \chi_{2}\right)\left[\prod_{i}\left(r+\delta_{i}\right)-\chi_{1} \chi_{2}\right] c_{1} c_{2}}, & i, j=(1,2), i \neq j
\end{array}
$$

Otherwise, if $\sum_{i} \frac{\left(r+\delta_{j}\right) a_{i}+\chi_{i} a_{j}}{\left[\prod_{i}\left(r+\delta_{i}\right)-\chi_{1} \chi_{2}\right] c_{i}} \geq 1$, the professor is hard working, and we have the following types of steady state:

i) If $\left[\prod_{i}\left(r+\delta_{i}\right)-\chi_{1} \chi_{2}\right] c_{j}+\left(r+\delta_{j}-\chi_{j}\right) a_{i}-\left(r+\delta_{i}-\chi_{i}\right) a_{j}>0$ for both $i, j$, and the RHS of (25) is non-negative, $i=1,2$, then the steady state is given by:

$$
\begin{aligned}
& u_{i}^{b s}=\frac{1}{\sum_{i} c_{i}}\left[c_{j}+\frac{\left(r+\delta_{j}-\chi_{j}\right) a_{i}-\left(r+\delta_{i}-\chi_{i}\right) a_{j}}{\prod_{i}\left(r+\delta_{i}\right)-\chi_{1} \chi_{2}}\right] \\
& x_{i}^{b s}=\frac{1}{\left(\delta_{1} \delta_{2}-\chi_{1} \chi_{2}\right) \sum_{i} c_{i}}\left\{\delta_{j} c_{j}+\chi_{j} c_{i}+\frac{\left(\delta_{j}-\chi_{j}\right)\left[\left(r+\delta_{j}-\chi_{j}\right) a_{i}-\left(r+\delta_{i}-\chi_{i}\right) a_{j}\right]}{\prod_{i}\left(r+\delta_{i}\right)-\chi_{1} \chi_{2}}\right\}
\end{aligned}
$$

ii) If $\left[\prod_{i}\left(r+\delta_{i}\right)-\chi_{1} \chi_{2}\right] c_{j}+\left(r+\delta_{j}-\chi_{j}\right) a_{i}-\left(r+\delta_{i}-\chi_{i}\right) a_{j}>0$ and $\left[\prod_{i}\left(r+\delta_{i}\right)-\chi_{1} \chi_{2}\right] c_{i}$ $+\left(r+\delta_{i}-\chi_{i}\right) a_{j}-\left(r+\delta_{j}-\chi_{j}\right) a_{i} \leq 0$, then at the steady state, a full-time effort is devoted to competency $i$, that is, $u_{i}=1$ and $u_{j}=0$, and:

$$
x_{i}^{b s}=\frac{\delta_{j}}{\delta_{1} \delta_{2}-\chi_{1} \chi_{2}}, \quad x_{j}^{b s}=\frac{\chi_{i}}{\delta_{1} \delta_{2}-\chi_{1} \chi_{2}}, \quad i, j=(1,2), i \neq j
$$

\section{Proof. A4.}


Under bilateral spillovers, two cases are distinguished, depending on the fact that the joint obsolescence effect is either weaker or larger than the joint effect of bilateral spillovers. In the first case, a sufficiently large discounting rate (tantamount to tight institutional control mechanisms) rules out the existence of an steady state, while loose control mechanisms directly drive the professor to the Apathetic status.

In the second case, where the joint obsolescence effect is greater than the joint effect of bilateral spillovers, an increase in the reward margin for one academic competency implies a greater interior steady state effort in both academic competencies. As long as the effort constraint is not binding, the school's management can encourage scholars to increase their efforts by increasing their compensation. In the hard-working case, as for the previous configurations, a marginal increase in the reward margin of one academic competency increases the corresponding interior steady state effort and decreases, by the same proportion, the other competency's interior steady state effort.

Keeping with the second case, here, too, tighter control mechanisms reduce the interior steady state academic profile. For symmetric reward margins, depreciation rates and spillover effects, the discounting rate has no influence on the hard-working steady state. On the other hand, the academic competencies increase with both incoming and outgoing spillover effects in the interior and the full-time activity steady states. In the hard-working case, each competency increases with outgoing spillover, but the impact of incoming spillover effect is ambiguous. This suggests the existence of a threshold value for the incoming spillover effect, above which a substitution effect occurs between the steady state competencies.

Lemma 5. For no, unilateral and bilateral spillovers between academic competencies with joint depreciation rates greater than joint spillover rates, the transversality conditions are fulfilled, respectively.

\section{Proof. A5.}


Given that the control constraints are linear and the Hamiltonian is a sum of linear and strictly concave quadratic functions, the Hamiltonian is strictly concave in both controls. Additionally, the Hamiltonian is linear in the state variables. This implies that the optimality conditions for each separate Hamiltonian, including the limiting transversality conditions, are also sufficient (e.g., Grass et al., 2008). We therefore conclude with the following theorem.

\section{Theorem.}

i) Under no or unilateral spillover between academic competencies, the steady states determined by Lemma 2 and Corollary 1, respectively, are globally optimal. The steady state is a saddle-point in both cases, and the convergence to the steady state is monotonic.

ii) Under bilateral spillovers,

- If the joint obsolescence effect is weaker than the joint effect of bilateral spillovers, i.e., $\delta_{1} \delta_{2}<\chi_{1} \chi_{2}$, Lemma 3 determines a globally optimal steady state, which results in zero competencies. The steady state academic profile has the saddle-point property and the optimal path converging to the steady state is monotonic.

- Otherwise, if $\delta_{1} \delta_{2}>\chi_{1} \chi_{2}$, Lemma 4 determines a globally optimal steady state. The steady state academic profile has the saddle-point property and the optimal path converging to the steady state is monotonic.

\section{Proof. A6.}

Comparing the steady state efforts and competencies respectively under no, unilateral and bilateral spillovers from (16), (11) and (22), and (16), (12) and (23) for the interior solution, on the one hand, and from (18), (15) and (26) for the full-time activity solutions, on the other hand, prove the following results.

Proposition. The steady state academic efforts and competencies in the case of bilateral spillovers with joint depreciation rates bigger than joint spillover rates, are larger than those 
for unilateral spillover, which are larger than those under no spillover both in the interior and full-time activity solutions.

The implementation of bilateral spillovers leads faculty members to improve their interior efforts by adding to and developing their own competencies. Each competency's incoming spillover effect is amplified by such improvements in the other competency's related effort, while no substitution effect between the steady state interior efforts occurs.

Bilateral spillovers are, accordingly, supportive of higher effort in the interior solution as well as in the full-time activity solutions, but as shown in the theorem, this solution is both desirable and locally stable only if the joint spillover effects are not too powerful. Therefore, institutions aiming to foster their faculty members' long run optimal competencies should favor academic structures consistent with positive but relatively weak bilateral spillovers. Otherwise, institutions risk some of their faculty moving toward either trivial or diverging steady state, depending on the tightness of the institutional control mechanisms. Note that this condition does not necessarily require that each competency's depreciation rate be larger than the spillover effect from the other competency. Rather, it allows for configurations where a strong (weak) spillover effect from a slowly depreciating academic competency is matched with a weak (strong) spillover effect from a quickly depreciating academic competency.

Lemma 6. Consider bilateral spillovers between academic competencies. If either $\delta_{1} \delta_{2}=\chi_{1} \chi_{2}$ or $\delta_{1} \delta_{2}<\chi_{1} \chi_{2}$ and $r>\sqrt{\left(\delta_{i}-\delta_{j}\right)^{2} / 4+\chi_{1} \chi_{2}}-\sum_{i} \delta_{i} / 2$, then the academic competencies have the following increasing paths over time, that is:

$$
X_{i}(t)=\frac{\left(f_{i} e^{-h t / 2}+f_{j} e^{k t / 2}\right) x_{i 0}-2 \chi_{j}\left(e^{-h t / 2}-e^{k t / 2}\right) x_{j 0}}{2 m}
$$




$$
\begin{array}{r}
+\frac{\left[\left(\delta_{j} f_{j}-2 \chi_{i} \chi_{j}\right) e^{-h t / 2}-\left(\delta_{j} f_{j}+2 \chi_{i} \chi_{j}\right) e^{k t / 2}+2 \delta_{j} m\right]\left[\left(r+\delta_{j}\right) a_{i}+\chi_{i} a_{j}\right]}{2 m\left(\delta_{i} \delta_{j}-\chi_{i} \chi_{j}\right)\left[\prod_{i}\left(r+\delta_{i}\right)-\chi_{1} \chi_{2}\right] c_{i}} \\
+\frac{\chi_{j}\left(k e^{-h t / 2}-h e^{k t / 2}+2 m\right)\left[\left(r+\delta_{i}\right) a_{j}+\chi_{j} a_{i}\right]}{2 m\left(\delta_{i} \delta_{j}-\chi_{i} \chi_{j}\right)\left[\prod_{i}\left(r+\delta_{i}\right)-\chi_{1} \chi_{2}\right] c_{j}}
\end{array}
$$

$i, j=(1,2), i \neq j$, for interior steady state efforts given from (22), and:

$$
\begin{aligned}
& X_{i}(t)=\frac{\left(f_{i} e^{-h t / 2}+f_{j} e^{k t / 2}\right) x_{i 0}-2 \chi_{j}\left(e^{-h t / 2}-e^{k t / 2}\right) x_{j 0}}{2 m} \\
& +\frac{\left[\left(\delta_{j} f_{j}-2 \chi_{i} \chi_{j}\right) e^{-h t / 2}-\left(\delta_{j} f_{j}+2 \chi_{i} \chi_{j}\right) e^{k t / 2}+2 \delta_{j} m\right]}{2 m\left(\delta_{i} \delta_{j}-\chi_{i} \chi_{j}\right) \sum_{i} c_{i}}\left[c_{j}+\frac{\left(r+\delta_{j}-\chi_{j}\right) a_{i}-\left(r+\delta_{i}-\chi_{i}\right) a_{j}}{\prod_{i}\left(r+\delta_{i}\right)-\chi_{1} \chi_{2}}\right] \\
& +\frac{\chi_{j}\left(k e^{-h t / 2}-h e^{k t / 2}+2 m\right)}{2 m\left(\delta_{i} \delta_{j}-\chi_{i} \chi_{j}\right) \sum_{i} c_{i}}\left[c_{i}+\frac{\left(r+\delta_{i}-\chi_{i}\right) a_{j}-\left(r+\delta_{j}-\chi_{j}\right) a_{i}}{\prod_{i}\left(r+\delta_{i}\right)-\chi_{1} \chi_{2}}\right]
\end{aligned}
$$

$i, j=(1,2), i \neq j$, for hard-working steady state efforts given from (24), where $f_{i} \equiv m+\delta_{i}-\delta_{j}>0, h \equiv m+\sum_{i} \delta_{i}>0, k \equiv m-\sum_{i} \delta_{i}>0, m \equiv \sqrt{\left(\delta_{i}-\delta_{j}\right)^{2}+4 \chi_{i} \chi_{j}}>0$, and the initial

conditions are $x_{i}(0)=x_{i 0} \geq 0, i=1,2$.

\section{Proof. A7.}

This result provides some insights to the no steady state situation that arises with bilateral spillovers between academic competencies and joint depreciation rates lower than joint spillover rates. Lemma 6 shows that in both the interior and the hard-working case, the system features an increasing trend of the academic competencies over time. A university would definitely enjoy the situation where the professor makes constant effort in both activities to permanently improve both competencies over time. When conditions for this appealing outcome are fulfilled (joint spillover rates are higher than joint depreciation rates), it makes sense for academic institutions to implement tight control mechanisms to avoid the corner 
Apathetic solution. An interesting feature of this solution is that while the controls are steady, the state variables are not. This is a direct consequence of the assumption of linear spillover effects via the state separability property. Though the paths of academic competencies grow progressively, they increase more slowly than the discounting rate (as by assumption $r>k / 2$ ) and they therefore do fulfil the transversality conditions that guarantee that the objective function is finite. As a result, we cannot rule out that these trajectories are optimal.

The model solution and the policy implications can be analyzed in a more intuitive way by means of phase diagrams. Figures $2 \mathrm{a}$ and $2 \mathrm{~b}$ represent the phase diagrams and the steady state solutions in the control space for the situation where there is no spillover between the academic competencies. Point $\mathrm{D}$ indicates the interior solution (2a), and points $\mathrm{D}_{1}, \mathrm{D}_{2}$ and $\mathrm{D}_{3}$ indicate the possible hard-working solutions (2b).

2a. Interior solution case

2b. Hard-working cases

Figures 2a-2b. Phase diagrams in the control space for the case with no spillover

In both figures, the steady state $\mathrm{O}$ reflects the situation where no effort is made in either activity and accordingly, both academic competencies decline over time. This corresponds to the Apathetic academic profile in our typology (Figure 1). Only a Star profile professor will steadily improve his competencies in both research and teaching. However, the Star profile is only obtained at or above the interior solution D, within the isosector $\dot{u}_{i}^{n b} \geq 0, i=1,2$, notably along the stable branch leading to the hard-working steady state $\mathrm{D}_{1}$ on the effort constraint line. Out of the hard-working solution $\mathrm{D}_{1}$ on the effort constraint line, since $\dot{u}_{i}=-\dot{u}_{j}, \quad i, j=(1,2), i \neq j$, a Specialized profile professor is directly reached by continuously improving the competencies in the relevant field of specialization (research or teaching), while the other competency is decreased over time, until either the teacher profile in $\mathrm{D}_{2}$, or the researcher profile in $\mathrm{D}_{3}$ is reached. A less direct path to specialization from above the interior solution D consists in continuously improving one competency while 
keeping the other constant (i.e., both $\dot{u}_{i}>0$ and $\dot{u}_{j}=0, i, j=(1,2), i \neq j$ ), until the effort constraint is binding, then to increase effort in the competency of specialization while reducing effort in the other competency.

It is noteworthy that the various steady states depicted in the phase diagrams could not be reached depending on the initial state conditions. Instead, for a given parameter constellation, the initial values of the optimal controls will always be in the basin of attraction (in the control space) of the same steady state regardless of the initial values of the states. A change of parameter would therefore be needed to move to the initial control to the basin of another steady state.

In the context of a finite time horizon, i.e., $t \in[0, T], T<\infty$, terminal values for the optimal controls inferred from salvage values of $x_{i}(t), i=1,2$, could lead to determine optimal paths from initial effort levels for a given parameter set. This approach is illustrated in figure 2a for salvaged values of $x_{i}(T)$ and $x_{i}^{\circ}(T), i=1,2$, respectively.

Notice that the isoclines $\dot{u}_{i}^{n b}=0, i=1,2$, can be interpreted as long-run barriers to permanence for junior members of the academic profession. These barriers often correspond to tenure, an organizational feature that prevails in a number of leading American academic institutions. To minimize the rate of Apathetic profiles, one possibility for academic institutions is to recruit new faculty in a selective way such that their initial efforts in either or both academic activities are beyond the locus $\dot{u}_{i}^{n b}<0, i=1,2$. The selectivity level is subject to variation, e.g., by exerting stronger influence on the faculty's time preference through tighter control mechanisms. However, tighter control mechanisms result in lowering the long-run barriers to permanence, which then lead to Apathetic profiles being promoted to tenured position. Reducing Apathetic profiles could thus result in a greater risk of overtenured faculty (see Vaupel, 1981). One way to offset such effect would be to simultaneously 
increase the reward margin of both competencies. This would raise long-run barriers to permanence, which would give rise to a higher long-run attrition rate of faculty. Further, this might lead to a binding effort constraint, and the disappearance of the Star profile. This eventuality would impose to also relax the effort constraint, e.g., by reducing the requirements in terms of teaching load (e.g., by expanding adjunct faculty) or by enhancing the research infrastructure, among other possibilities.

Note that the adjunction of administrative service (e.g., management of departments, programs or projects) to basic academic activities in the previous figures would result in an inward shift of the effort constraint line with three negative consequences. Firstly, an increase in the relative proportion of Apathetic profiles through a decline in the number of both specialized and Star profiles; secondly, a reduction in the variety of the faculty's composition, such that the specialized profiles become prevalent; for an extremely tight effort constraint, the Star profile vanishes; and finally, an inflexion in the competencies path of specialized profiles, i.e., the highest potential competency level declines in both activities.

We turn now to the case of unilateral and bilateral spillovers. Figures 3a and 3b depict the phase diagrams and the steady states in the control space for the situations corresponding to unilateral spillover (3a) and bilateral spillovers (3b) between the academic competencies. The phase diagram for bilateral spillovers (3b) corresponds to the case where the joint effect of depreciation rates of academic competencies is greater than the joint effect of bilateral spillovers between the academic competencies, i.e., $\delta_{1} \delta_{2}>\chi_{1} \chi_{2}$.
3a. Case with unilateral spillover
3b. Case with bilateral spillovers

Figures 3a-3b. Phase diagrams in the control space for the cases with unilateral and bilateral spillovers Under bilateral spillovers between academic competencies, the interior steady state increases with both competencies' spillover effects. Compared to the configurations with no or unilateral spillover, the scope for the Apathetic profile is narrowed but not fully eliminated. The Star profile is also in scarce supply because professors have large incentives to specialize. 
In fact, the major career choice or a professor here lies between the Teacher profile and the Researcher profile. Specialization is reached straightforwardly along a path starting from a sufficiently high initial effort level in one competency only. Yet many scholars would claim that such specialization should be avoided and that their management should support the development of a faculty made up of scholars able to deliver both high quality research and high quality teaching (our Star profile). Note that once either teaching or research experience has been accumulated, every specialized profile can expect a continuous improvement in both academic competencies. As a result, the need for the Star profile is reduced.

Another important difference between the bilateral spillovers case and the configurations with no or unilateral spillover is that the selectivity levels can now be lowered so that the initial effort level required from new faculty members in either or both academic activities is reduced. That is, bilateral spillovers improve the composition of the faculty without lowering the interior steady state. Because the conditions of successful specialization are improved, the rate of Apathetic profiles is minimized. Note that an increase in the magnitude of bilateral spillovers enhances the interior steady state competencies.

Overall, when there are bilateral spillovers with joint depreciation rates greater than joint bilateral spillovers, academic institutions are allowed to hire new faculty members who have shown a sufficiently high initial level of effort in only one of the two academic activities. Accordingly, bilateral spillovers enable a professor to more easily avoid apathetic status, as illustrated in figure 3b with the optimal paths starting from initial effort levels (each involved by a specific parameter set) below the interior steady state and reaching the terminal values for the optimal controls inferred from salvaged values of $x_{i}(T)$ and $x_{i}^{\circ}(T), i=1,2$, respectively. That is, specialization is possible both from low and large (i.e., lower and larger than the interior steady state values) initial effort levels. Academic institutions seeking to influence the distribution of specialized profiles within their faculty should further consider 
the consequences of cross-fertilization between the two competencies and refrain from focusing solely on the competency they wish to strengthen as bilateral spillovers often turn specialized profiles into flexible competencies. Finally, academic institutions that increase their administrative service requirements of faculty find that they lose the most competent profiles in both activities; this conclusion should be qualified by the obvious need for managers with research and teaching experience in managing programmes and research projects in a world where academic funding depends more extensively on external competitive funding (Etzkowitz, 2003; Carayol and Matt, 2004).

\section{Conclusion}

The social mission of higher education institutions includes two essential goals: delivering high quality education programs and contributing to advancing knowledge by producing original research. The main input into this two-dimensional flow of services to society is provided by a special category of staff, their faculty.

Our paper contributes to the debate on how to improve the performance of academic institutions by analyzing the inter-temporal decision of a utility-maximizing professor who can divide his work time and effort between research and teaching. To do so, we developed a two-state equation capital accumulation model. One key element of the analysis is the existence of institutionally based spillovers between competencies in teaching and competencies in research, which are related to the implementation of an appropriate organizational structure by the academic institution. Such organizational design can involve the creation of a PhD program, which is then used to leverage the research capacities of the school, and the implementation of policies to transfer research into Master of Science teaching. The organizational design may also involve inviting students in various programs to collaborate on research projects (as research assistants or subjects in experimental research), or implementing work rules at the department levels favoring the cross fertilization of 
competencies at the individual's level. On the other hand, teaching can be organized to bring a positive contribution to research if the school decides to specialize in advanced teaching programs requiring higher abstraction, stronger knowledge, and a more powerful methodology to address the teaching goals, if it encourages writing of textbooks and case studies convertible into applied research.

The main findings can be summarized as follows:

- In the long run, the interior competencies with bilateral spillovers are larger than those with no or unilateral spillover; in this respect, gearing the academic organization toward the emergence of bilateral spillovers could be beneficial.

- However, the steady state academic profile is always locally stable under no or unilateral spillover, while it is locally stable under bilateral spillovers only for specific conditions. This finding raises some doubts about the overall desirability of bilateral spillovers.

- Long-run stability under bilateral spillovers can be achieved only if the academic institution takes into account the magnitude of the competencies' depreciation rates. As a managerial heuristic, the more quickly one academic competency becomes obsolete, the larger the spillover that should be allowed because it does not harm the long-run stability of the system.

In sum, our analysis indicates that the depreciation rate of competencies should guide the nature of the organizational shift. Institutionally based bilateral spillovers can improve, to a certain extent, academic institutions' overall performances by developing more competent, flexible, and homogenous faculty members. However, a too powerful bilateral spillover effect can be problematic if institutional control mechanisms are loose. In this case, the professor can be driven toward the apathetic status where he rests on his past achievements and forego efforts to further improve human capital. Conversely, if the control mechanisms are tight enough, by setting an optimal steady effort, the professor will continuously improve his 
competencies. Achieving an optimal mix of academic profiles is thus a matter of subtle balance between institutional control mechanisms and bilateral spillovers between academic competencies.

The proposed model can be extended in various ways. In this paper, we assumed a linear influence of the institutionally based spillover effects. An interesting research development would consider a nonlinear influence of the mutual spillover effects along with concaveconvex effort costs where the concave part would be an approximation of fixed costs. Such assumptions may generate more complex solution paths, e.g., multiple equilibria and Skiba sets $^{6}$. Furthermore, other activities, such as consulting and administrative services, were not introduced in the set of decision variables of our model. It would be interesting to consider one extra activity without extending the state space by including in the objective criteria additional revenue generated by an unbinding effort constraint. This would clarify the magnitude of incentives that contribute to diverting professors from exclusive hard work in the two basic academic activities. In this paper the implementation of institutionally based spillover effects was considered as exogenously given. Another possible extension would study the dynamic game between the professor and the academic institution where the latter now decides at cost on the extent of the bilateral spillovers between teaching and research in a continuous rather than a discrete way. A comparison between open-loop and closed-loop Nash equilibria could then be established to determine whether institutionally based bilateral spillovers provide some incentives for professors to free ride. Finally, our model relies on the assumption of a representative professor having no interaction with his colleagues. It might be interesting to analyze how competition among professors impacts their optimal effort allocation between the two academic competencies.

\footnotetext{
${ }^{6}$ The authors are grateful to one anonymous reviewer for this suggestion.
} 


\section{Acknowledgements}

The authors acknowledge very helpful comments from Associate Editor, Herbert Dawid and two anonymous referees. They also thank Gustav Feichtinger, Peter Kort, Eugene Khmelnitsky, Engelbert Dockner, Richard Hartl, and Steffen Jørgensen for constructive suggestions on an early draft. The usual disclaimer applies. 


\section{Appendix}

A1. To compute the interior solution with $\chi_{i}>0$ and $\chi_{j}=0, i, j=(1,2), i \neq j$, we solve the canonical system in the state-costate space given by (1)-(2)-(6) where $u_{i}, i=1,2$, is replaced by its expression in (9). Using (9) leads to characterize the system's steady state in (11)-(12) with $\eta^{S}=\omega_{i}^{S}=0, i=1,2$. To determine the hard-working solution, we solve the system (1)(2)-(3)-(6)-(9) and get (13)-(14) with $\eta^{s}=\frac{1}{\sum_{i} c_{i}}\left[\frac{\sum_{i}\left(r+\delta_{i}\right) a_{j} c_{i}+\chi_{i} a_{j} c_{j}}{\prod_{i}\left(r+\delta_{i}\right)}-\prod_{i} c_{i}\right]$ and $\omega_{i}=0, i=1,2$. In the full-time activity case, we set $u_{i}=1$ and $u_{j}=0, i, j=(1,2), i \neq j$, and solve the system (1)-(2)-(6)-(9) to get (15)-(16) with $\eta^{s}=\frac{\left(r+\delta_{j}\right) a_{i}+\chi_{i} a_{j}}{\prod_{i}\left(r+\delta_{i}\right)}-c_{i}$ and $\omega_{j}^{S}=\frac{\left(r+\delta_{j}\right) a_{i}-\left(r+\delta_{i}-\chi_{i}\right) a_{j}}{\prod_{i}\left(r+\delta_{i}\right)}-c_{i}, i, j=(1,2), i \neq j$

A2. For the interior solution with $\chi_{i}=0, i=1,2$, we use (9) to solve the system (1)-(2)-(6) and get (16), with $\eta^{s}=\omega_{i}^{s}=0, i=1,2$. The resolution of (1)-(2)-(3)-(6)-(9) leads to the hard-working solution in (17) with $\eta^{s}=\frac{1}{\sum_{i} c_{i}}\left[\frac{\sum_{i}\left(r+\delta_{i}\right) c_{i} a_{j}}{\prod_{i}\left(r+\delta_{i}\right)}-\prod_{i} c_{i}\right]$ and $\omega_{i}=0, i=1,2$. In the full-time activity case, we set $u_{i}=1$ and $u_{j}=0, i, j=(1,2), i \neq j$, and solve (1)-(2)(6)-(9) to obtain (18) with $\eta^{s}=\frac{a_{i}}{\left(r+\delta_{i}\right)}-c_{i}$ and $\omega_{j}^{s}=\frac{a_{i}}{r+\delta_{i}}-\frac{a_{j}}{r+\delta_{j}}-c_{i}, i, j=(1,2), i \neq j . \square$

A3. Regarding the case with $\chi_{i}>0, i=1,2$, the resolution of the equations in (6) shows that the costate variables are either both negative or both negative, which rules out the existence of the case where $u_{i}^{n b s}=0$ and $0<u_{j}^{n b s}<1, i, j=(1,2), i \neq j$. Obviously, if $\delta_{1} \delta_{2}<\chi_{1} \chi_{2}$, there is neither interior nor full-time activity steady state. Assuming that 
$r>\sqrt{\left(\sum_{i} \delta_{i} / 2\right)^{2}+\chi_{1} \chi_{2}-\delta_{1} \delta_{2}}-\sum_{i} \delta_{i} / 2$ and $\sum_{i} \frac{\left(r+\delta_{j}\right) a_{i}+\chi_{i} a_{j}}{\left[\prod_{i}\left(r+\delta_{i}\right)-\chi_{1} \chi_{2}\right] c_{i}} \geq 1$, a hard-working steady state exists if and only if both $c_{j}>-\frac{\left(r+\delta_{j}-\chi_{j}\right) a_{i}-\left(r+\delta_{i}-\chi_{i}\right) a_{j}}{\prod_{i}\left(r+\delta_{i}\right)-\chi_{1} \chi_{2}}$ and $\frac{\delta_{j} c_{j}+\chi_{j} c_{i}}{\delta_{j}-\chi_{j}}>-\frac{\left(r+\delta_{j}-\chi_{j}\right) a_{i}-\left(r+\delta_{i}-\chi_{i}\right) a_{j}}{\prod_{i}\left(r+\delta_{i}\right)-\chi_{1} \chi_{2}}$. It can be shown that these conditions require that $\delta_{j}<\chi_{j}$ and $\left(r+\delta_{j}-\chi_{j}\right) a_{i}>\left(r+\delta_{i}-\chi_{i}\right) a_{j}, i, j=(1,2), i \neq j$. As the latter condition can not hold for $i=1,2$, there is no hard-working steady state. Conversely, if $r \in] 0, \sqrt{\left(\sum_{i} \delta_{i} / 2\right)^{2}+\chi_{1} \chi_{2}-\delta_{1} \delta_{2}}-\sum_{i} \delta_{i} / 2\left[\right.$, the only possible steady state is $u_{i}^{b s}=x_{i}^{b s}=0, i=1,2 . \square$ A4. In the case with $\chi_{i}>0, i=1,2$, and $\delta_{1} \delta_{2}>\chi_{1} \chi_{2}$, we use (9) to solve the system (1)-(2)(6) and get the interior solution in (21)-(22), with $\eta^{S}=\omega_{i}^{S}=0, i=1,2$. On the other hand, the resolution of (1)-(2)-(3)-(6)-(9) leads to the hard-working solution in (24)-(25) with $\eta^{s}=\frac{1}{\sum_{i} c_{i}}\left\{\frac{\sum_{i}\left[\left(r+\delta_{i}\right) a_{j} c_{i}+\chi_{i} a_{j} c_{j}\right]}{\prod_{i}\left(r+\delta_{i}\right)-\chi_{1} \chi_{2}}-\prod_{i} c_{i}\right\}$ and $\omega_{i}=0, i=1,2$. Finally, setting $u_{i}=1$ and $u_{j}=0, \quad i, j=(1,2), i \neq j$, and solving (1)-(2)-(6)-(9) yields the full-time activity solutions in (26) with $\eta^{s}=\frac{\left(r+\delta_{j}\right) a_{i}+\chi_{i} a_{j}}{\prod_{i}\left(r+\delta_{i}\right)-\chi_{1} \chi_{2}}-c_{i}$ and $\omega_{j}^{S}=\frac{\left(r+\delta_{j}-\chi_{j}\right) a_{i}-\left(r+\delta_{i}-\chi_{i}\right) a_{j}}{\prod_{i}\left(r+\delta_{i}\right)-\chi_{1} \chi_{2}}-c_{i}$, $i, j=(1,2), i \neq j$

A5. To show that the transversality conditions are fulfilled, we use the catching-up optimality criterion. For the interior solution, we get:

$$
\lim _{t \mapsto+\infty} e^{-r t} \lambda_{i}(t) x_{i}^{n b}(t)=\frac{e^{-r t} a_{i}^{2}}{\delta_{i}\left(r+\delta_{i}\right)^{2} c_{i}}=0
$$

under no spillover, and respectively: 


$$
\begin{aligned}
& \lim _{t \mapsto+\infty} e^{-r t} \lambda_{i}(t) x_{i}^{n b}(t)=\frac{\left[\left(r+\delta_{j}\right) a_{i}+\chi_{i} a_{j}\right]^{2}}{\delta_{i}\left(r+\delta_{i}\right)^{2}\left(r+\delta_{j}\right)^{2} c_{i}}=0 \\
& \lim _{t \mapsto+\infty} e^{-r t} \lambda_{j}(t) x_{j}^{n b}(t)=\frac{e^{-r t} a_{j}\left\{\delta_{i} c_{i}\left(r+\delta_{i}\right) a_{j}+\chi_{i} c_{j}\left[\left(r+\delta_{j}\right) a_{i}+\chi_{i} a_{j}\right]\right\}}{\delta_{i} \delta_{j}\left(r+\delta_{i}\right)\left(r+\delta_{j}\right)^{2} c_{i} c_{j}}=0
\end{aligned}
$$

under unilateral spillover from competency $i$ to competency $j, i, j=(1,2), i \neq j$, and:

$$
\lim _{t \mapsto+\infty} e^{-r t} \lambda_{i}(t) x_{i}^{n b}(t)=\frac{e^{-r t}\left[\left(r+\delta_{j}\right) a_{i}+\chi_{i} a_{j}\right]\left\{\delta_{j} c_{j}\left[\left(r+\delta_{j}\right) a_{i}+\chi_{i} a_{j}\right]+\chi_{j} c_{i}\left[\left(r+\delta_{i}\right) a_{j}+\chi_{j} a_{i}\right]\right\}}{\left(\delta_{i} \delta_{j}-\chi_{i} \chi_{j}\right)\left[\left(r+\delta_{i}\right)\left(r+\delta_{j}\right)-\chi_{i} \chi_{j}\right]^{2} c_{i} c_{j}}=0
$$

under bilateral spillovers between academic competencies $, i, j=(1,2), i \neq j$.

For the hard-working situation, we get:

$$
\lim _{t \mapsto+\infty} e^{-r t} \lambda_{i}(t) x_{i}^{b}(t)=\frac{e^{-r t} a_{i}\left[a_{i}-a_{j}+\left(r+\delta_{j}\right) c_{j}-\left(\delta_{i}-\delta_{j}\right) \eta^{s}\right]}{\delta_{i}\left(r+\delta_{i}\right) \sum_{i}\left(r+\delta_{i}\right) c_{i}}=0
$$

under no spillover, and:

$$
\begin{aligned}
& \lim _{t \mapsto+\infty} e^{-r t} \lambda_{i}(t) x_{i}^{b}(t)=\frac{\left[\left(r+\delta_{j}\right) a_{i}+\chi_{i} a_{j}\right]\left\{\delta_{j}\left[a_{i}-a_{j}+\left(r+\delta_{j}+\chi_{i}\right) c_{j}-\left(\delta_{i}-\delta_{j}-\chi_{i}\right) \eta^{s}\right]+\chi_{i}\left(r+\delta_{i}\right) c_{i}\right\}}{\delta_{i} \delta_{j}\left(r+\delta_{i}\right)\left(r+\delta_{j}\right)\left[\sum_{i}\left(r+\delta_{i}\right) c_{i}+\chi_{i} c_{j}\right]}=0 \\
& \lim _{t \mapsto+\infty} e^{-r t} \lambda_{j}(t) x_{j}^{b}(t)=\frac{e^{-r t} a_{j}\left[a_{j}-a_{i}+\left(r+\delta_{i}\right) c_{i}+\left(\delta_{i}-\delta_{j}-\chi_{i}\right) \eta^{s}\right]}{\delta_{i} \delta_{j}\left(r+\delta_{j}\right)\left[\sum_{i}\left(r+\delta_{i}\right) c_{i}+\chi_{i} c_{j}\right]}=0
\end{aligned}
$$

under unilateral spillover from competency $i$ to competency $j, i, j=(1,2), i \neq j$, and:

$$
\begin{aligned}
& \lim _{t \mapsto+\infty} e^{-r t} \lambda_{i}(t) x_{i}^{b}(t)= \\
& \frac{e^{-r t}\left[\left(r+\delta_{j}\right) a_{i}+\chi_{i} a_{j}\right]\left\{\left(\delta_{j}-\chi_{i}\right)\left[a_{i}-a_{j}-\left(\delta_{i}-\delta_{j}+\chi_{j}-\chi_{i}\right) \eta^{s}\right]+\chi_{i}\left(r+\delta_{i}+\chi_{j}\right) c_{i}+\delta_{j}\left(r+\delta_{j}+\chi_{i}\right) c_{j}\right\}}{\left(\delta_{i} \delta_{j}-\chi_{i} \chi_{j}\right)\left[\left(r+\delta_{i}\right)\left(r+\delta_{j}\right)-\chi_{i} \chi_{j}\right] \sum_{i}\left(r+\delta_{i}+\chi_{j}\right) c_{i}}=0
\end{aligned}
$$

under bilateral spillovers between academic competencies, $i, j=(1,2), i \neq j . \square$ 
A6. To check the stability of the interior steady state with no, unilateral and bilateral spillovers, respectively, we compute the Jacobian matrix associated with the canonical system (1)-(2)-(6) where $u_{i}, i=1,2$, is replaced by its expression in (9), that is:

$$
J^{n b}=\left[\begin{array}{cccc}
-\delta_{1} & \chi_{2} & 1 / c_{1} & 0 \\
\chi_{1} & -\delta_{2} & 0 & 1 / c_{2} \\
0 & 0 & r+\delta_{1} & -\chi_{1} \\
0 & 0 & -\chi_{2} & r+\delta_{2}
\end{array}\right]
$$

In the cases with no and unilateral spillover, the sum of the principal minors of $J^{n b}$ of order 2 minus the squared discount rate, $K^{n b}=-\delta_{1}\left(r+\delta_{1}\right)-\delta_{2}\left(r+\delta_{2}\right)$, is strictly negative, which rules out the existence of limit cycles (Dockner and Feichtinger, 1991). Since, in addition, the determinant $\left|J^{n b}\right|=\delta_{1} \delta_{2}\left(r+\delta_{1}\right)\left(r+\delta_{2}\right)$, is strictly positive, the necessary and sufficient conditions for the steady state to be a saddle-point are fulfilled. Finally, as $\Omega^{n b}=\left(K^{n b}\right)^{2}-4\left|J^{n b}\right|=\left[\delta_{1}\left(r+\delta_{1}\right)-\delta_{2}\left(r+\delta_{2}\right)\right]^{2}>0$, the steady state is a saddle-node and the optimal path converges monotonically to it. In the case with bilateral spillovers, $\left|J^{n b}\right|=\left(\delta_{1} \delta_{2}-\chi_{1} \chi_{2}\right)\left[\left(r+\delta_{1}\right)\left(r+\delta_{2}\right)-\chi_{1} \chi_{2}\right], \quad K^{n b}=-\left[\delta_{1}\left(r+\delta_{1}\right)+\delta_{2}\left(r+\delta_{2}\right)+2 \chi_{1} \chi_{2}\right]<0, \quad$ and $\Omega^{n b}=\left[\delta_{1}\left(r+\delta_{1}\right)-\delta_{2}\left(r+\delta_{2}\right)\right]^{2}+4 \chi_{1} \chi_{2}\left(r+\delta_{1}+\delta_{2}\right)^{2}>0$. If $\delta_{1} \delta_{2}<\chi_{1} \chi_{2}$, then $\left|J^{n b}\right|>0$ if and only if $r \in] 0, r>\sqrt{\left(\delta_{i}+\delta_{j}\right)^{2} / 4+\chi_{i} \chi_{j}-\delta_{i} \delta_{j}}-\left(\delta_{i}+\delta_{j}\right) / 2[$. Accordingly, the corner solution is locally stable and the optimal path monotonically converges to it. Conversely, if $\delta_{1} \delta_{2}>\chi_{1} \chi_{2}$, then $\left|J^{n b}\right|>0$, that is, the interior steady state is a saddle-node and the optimal path monotonically converges to it. 
In the hard-working cases with no, unilateral and bilateral spillovers, respectively, the Jacobian matrix of the system (1)-(2)-(6) where $u_{i}$ is replaced by its expression in (10), $i=1,2$, is:

$$
J^{b}=\left[\begin{array}{cccc}
-\delta_{1} & \chi_{2} & 1 / \sum_{i} c_{i} & -1 / \sum_{i} c_{i} \\
\chi_{1} & -\delta_{2} & -1 / \sum_{i} c_{i} & 1 / \sum_{i} c_{i} \\
0 & 0 & r+\delta_{1} & -\chi_{1} \\
0 & 0 & -\chi_{2} & r+\delta_{2}
\end{array}\right]
$$

It can be easily shown that similar results than those of the interior case are obtained.

A7. Assuming that the controls $\left(u_{1}, u_{2}\right)$ are given constants, the system of (1)-(2) is solved in $\left(x_{1}(t), x_{2}(t)\right)$ for $x_{i}(0)=x_{i 0} \geq 0$. Then, substituting the expressions for the interior and hardworking steady state efforts, i.e., respectively, $\left(u_{1}^{n b s}, u_{2}^{n b s}\right)$ and $\left(u_{1}^{b s}, u_{2}^{b s}\right)$, from (22) and (24) and simplifying gives (28) and (29). 


\section{References}

Arnold, I.J., 2008. Course level and the relationship between research productivity and teaching effectiveness. Journal of Economic Education, Fall issue, 307-321.

Aron, R., 1970. Avez-vous lu Veblen? In: Veblen, T., Théorie de la Classe de Loisir. Gallimard, Paris.

Bachelard, G., 1934. La Formation de l’Esprit Scientifique. Gauthier-Villars, Paris.

Beath, J.A., Owen, R.F., Poyago-Theotoky, J., Ulph, D., 2003. Optimal incentives for income-generation in universities: the rule of thumb for the Compton tax, International Journal of Industrial Organization 21, 1301-1322.

Beath, J.A., Poyago-Theotoky, J., Ulph, D., 2012, University funding systems and their impact on research and teaching: A general framework, Economics: The Open Access, OpenAssessment E-Journal, 6, http://dx.doi.org/10.5018/economics-ejourlanl.ja.2012-2.

Becker, W.E., Jr, 1975. The university professor as a utility maximizer and producer of learning, research and income. Journal of Human Resources 10, 107-115.

Becker, W.E., Kennedy, P.E., 2006. The influence of teaching on research in economics. Southern Economic Journal 72, 747-759.

Besancenot, D., Faria, J.R., Vranceanu, R., 2009. Why Business Schools do so much research: A signaling explanation. Research Policy 38, 1093-1101.

Boudon, R., 1994. The Art of Self-Persuasion. Polity Press, London.

Carayol, N., Matt, M., 2004. Does research organization influence academic production? Laboratory level evidence form a large European university. Research Policy 33, 1081-1102.

Cassiman, B., Veugelers, R., 2002. R\&D cooperation and spillovers. Some empirical evidence from Belgium. American Economic Review 92, 1169-1184.

Courtault, J.-M., Kabanov, Y., 2002. Louis Bachelier - Aux Origines de la Finance Mathématique. Presses Universitaires Franc-Comtoises. 
Demski, J.S., Zymmerman, J.L., 2000. On 'research vs. teaching’: A long-term perspective. Accounting Horizons 14, 343-352.

Diamond, A.M., Jr, 1993. Economic explanations of the behaviour of universities and scholars. Journal of Economic Studies 20, 107-133.

Dockner, E., 1985. Local stability in optimal control problems with two state variables, in Feichtinger, G. (Ed.), Optimal Control Theory and Economic Analysis, vol. 2, North Holland, Amsterdam, 89-103.

Etzkowitz, H., 2003. Research groups as 'quasi-firms': the invention of the entrepreneurial university. Research Policy 32, 109-121.

Euwals, R., Ward, M.E., 2005. What matters most: teaching or research? Empirical evidence on the remuneration of British academics. Applied Economics 37, 1655-1672.

Fairweather, J.S., 2002. The mythologies of faculty productivity: Implications for institutional policy and decision making. The Journal of Higher Education 73, 26-48.

Faria, J.R., Loureiro, P.R.A., Mixon, F.G., Jr., Sachsida, A., 2013. Faculty promotion in academe: Theory and evidence from US economics departments. Journal of Economics and Econometrics 56, 1-27.

Friedrich, R.T, Michalak, S.J., Jr., 1983. Why doesn’t research improve teaching? Some answers from a small liberal arts college. Journal of Higher Education 54, 145-163.

Gautier, A., Wauthy, X., 2007. Teaching vs. research: A multi-tasking approach to multidepartment universities. European Economic Review 51, 273-295.

Gomez-Mejia, L.R., Balkin, D.B., 1992. Determinants of faculty pay: An agency theory perspective. Academy of Management Journal 35, 921-955.

Grass, D., Caulkins, J.P., Feichtinger, G., Tragler, G., Behrens, D.A., 2008. Optimal Control of Nonlinear Processes with Applications in Drugs, Corruption, and Terror. Springer, Berlin. 
Hattie, J., Marsh, H.W., 1996. The relationship between research and teaching - A metaanalysis. Review of Educational Research 66, 507-542.

Kuhn, T.S., 1962. The Structure of Scientific Revolutions. University of Chicago Press, Chicago.

Lovell, M., 1973. The production of economic literature: an interpretation. Journal of Economic Literature 11, 27-55.

Marsh, H.W., Hattie, J., 2002. The relation between research productivity and teaching effectiveness: complementary, antagonistic or independent constructs? Journal of Higher Education 73, 603-641.

Maske, K.L., Durdeen, G.C., Gaynor, P.E., 2003. Determinants of scholarly productivity among male and female economists. Economic Inquiry 41, 555-564.

McDowell, J.F., Melvin, M., 1983. The determinants of co-authorship: An analysis of the economic literature. Review of Economics and Statistics 62, 318-321.

Merton, R.K., 1957. Priorities in scientific discovery: A chapter in the sociology of science. American Sociological Review 22, 635-659.

Patinkin, D., 1973. Franck Knight as a teacher. American Economic Review, 63, 787-810.

Paul, C.W., Rubin, P.C., 1984. Teaching and research: The human capital paradigm. Journal of Economic Education, Spring, 142-147.

Popper, K., 1934. Logik Der Forschung. Springer, Vienna.

Treischmann, J.S., Dennis, A.R., Northcraft, G.B. Niemi, A.W., Jr., 2000. Serving multiple constituencies in business schools: M.B.A. program versus research performance. Academy of Management Journal 43, 1130-1141.

Vaupel, J.W., 1981. Over-tenured universities: The mathematics of reduction. Management Science 27, 904-913. 
Veblen, T., 1899. The Theory of the Leisure Class: An Economic Study in the Evolution of Institutions. Macmillan, New York. 


\begin{tabular}{|c|c|c|}
\hline & \multicolumn{2}{|c|}{ Research Effort } \\
\hline & Low & High \\
\hline Teaching High & Teacher Type & Flexible (Star) \\
\hline Effort Low & Apathetic & Researcher Type \\
\hline
\end{tabular}

Figure 1. Typology of effort profiles 


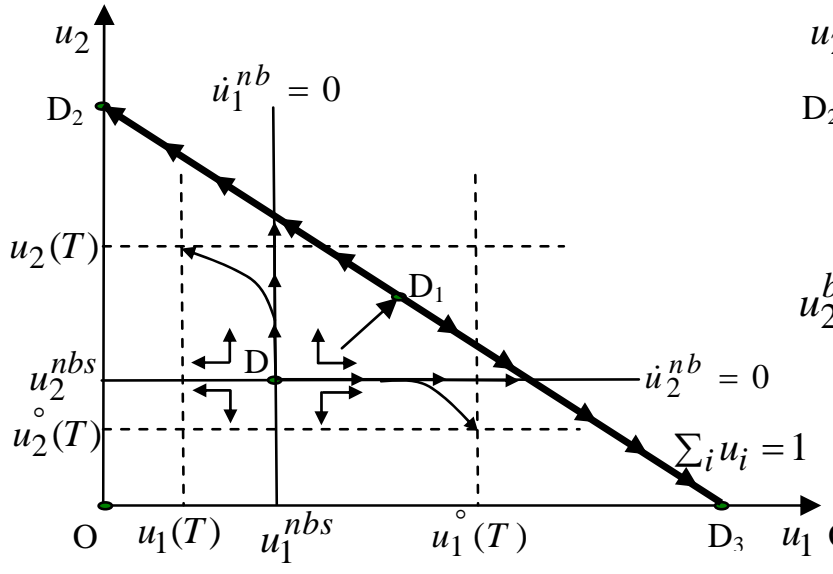

2a. Interior solution case

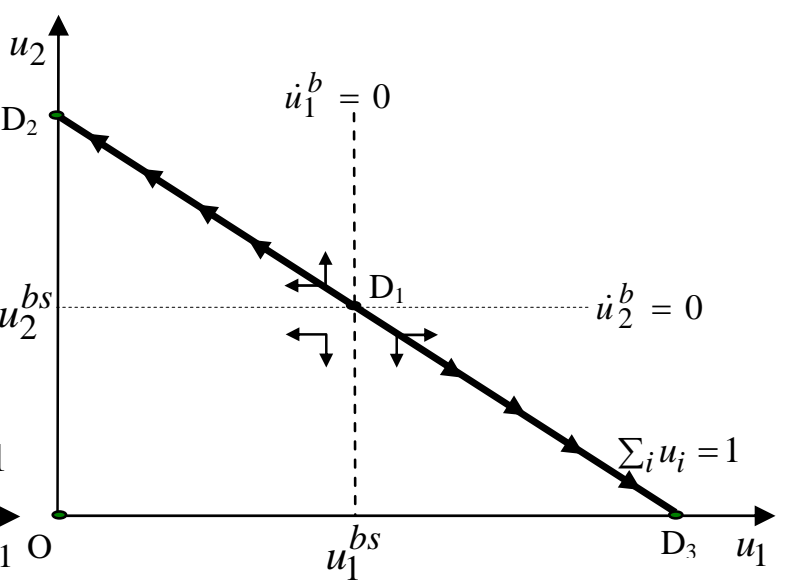

2b. Hard-working cases

Figures 2a-2b. Phase diagrams in the control space for the case with no spillover 


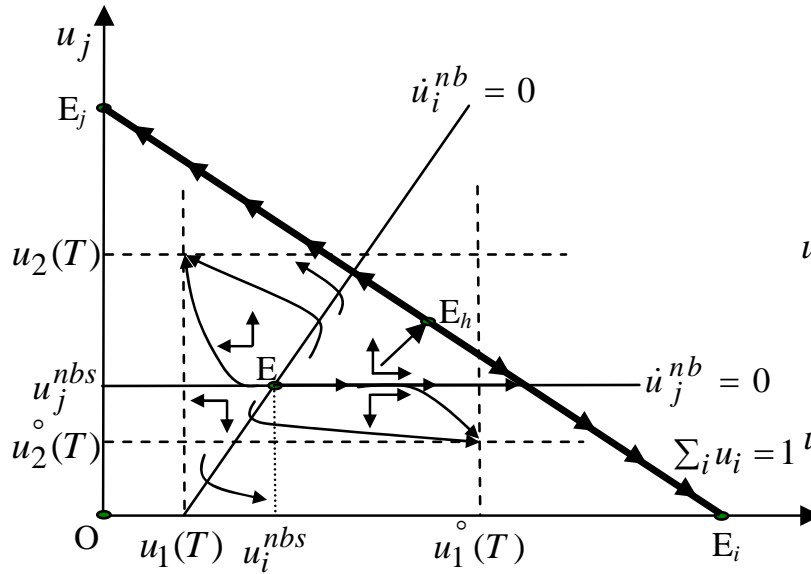

3a. Case with unilateral spillover

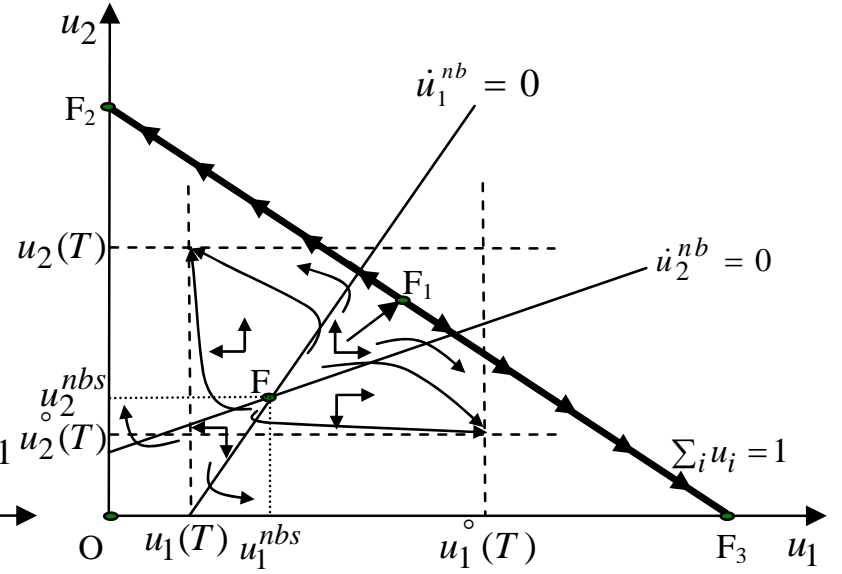

3b. Case with bilateral spillovers

Figures 3a-3b. Phase diagrams in the control space for the cases with unilateral and bilateral spillovers 
ESSEC Business School Avenue Bernard Hirsch BP 50105

95021 Cergy-Pontoise Cedex

France

Tél. +33(0)134433000

$\mathrm{Fax}+33(0) 134433001$

www.essec.fr

\section{ESSEC Executive Education} CNIT BP 230

92053 Paris-La Défense France

Têl. +33(0)146924900

Fax +33(0)1 46924990

http://formation.essec.fr

ESSEC Business School

Singapore Campus

100 Victoria Street

National Library Building \# 13-02

Singapore 188064

essecasia@essec.fr

Tél. +6568849780

Fax +6568849781

www.essec.edu

Informations

Alison Bougi

+33 (0)134433358

bougi@essec.fr

www.essec.fr

research.center@essec.fr

ISSN 1291-9616 